\title{
EDUKASI DENGAN PENDEKATAN PRINSIP DIABETES SELF MANAGEMENT EDUCATION (DSME) MENINGKATKAN PERILAKU KEPATUHAN DIET PADA PENDERITA DIABETES MELLITUS TIPE 2
}

\author{
Nadia Rohmatul Laili*, Yulis Setiya Dewi**, Ika Yuni Widyawati** \\ *Mahasiswa Program Studi Ilmu Keperawatan, Fakultas Keperawatan Universitas Airlangga \\ ** Staf Pengajar Fakultas Keperawatan Universitas Airlangga \\ Email: nadia280721@gmail.com
}

\begin{abstract}
Introduction: Diabetes Mellitus (DM) is one of the incurable cronic diseases. The patient's dietary obedience is a principal component in diabetes treatment success. One of the efforts to increase dietary obedience behavior in type 2 Diabetes Mellitus patients is using a Diabetes Self Management Education (DSME) principles approach. Diabetes Self Management Education (DSME) is the ongoing process of facilitating knowledge, skill and ability necessary for diabetes self care. The purpose of this study was to analyze the influence of DSME principles approach toward the dietary obedience behavior that consists of knowledge, attitude, and practice aspects in patients with type 2 Diabetes Mellitus at Puskesmas Kebonsari Surabaya. Methods: A quasy experimental design was used in this study with 24 people as the sample which taken by using purposive sampling and divided into two groups (treatment and control group). A structured questionnaire and daily meal note for seven days were used to collect the data. The data were analyzed by using Wilcoxon signed rank test and Mann Whitney $U$ test with significant level $\alpha \leq 0.05$. Result: The results showed that there was an influence of DSME principles approach after being applied to the treatment group and control group toward the dietary knowledge with the value of $p=0.004$ and $p=0.083$ respectively, the attitude of dietary obedience with $p=0.025$ and $p=0.083$ and the dietary obedience practice with $p=0.002$ and $p=0.564$. Discussion: The study showed that DSME approach had a significant influence toward the dietary obedience behavior in type 2 Diabetes Mellitus patients. DSME principles approach used learning based on patient empowerment and behavior strategies. Ongoing support also contributed in maintaining progress achieved so that resulting dietary obedience behavior in type 2 Diabetes Mellitus patients. Larger respondents, more proper instruments and longer duration of study are needed to get a better results of the study concerning diabetic patient's obedience in the future.
\end{abstract}

Keywords: Diabetes Self Management Education (DSME) principles approach, dietary obedience behavior, Diabetes Mellitus (DM)

\section{PENDAHULUAN}

Menurut American Diabetes Association (2005), DM tipe 2 merupakan suatu kelompok penyakit metabolik yang hanya dapat diterapi dengan mengendalikan kadar glukosa agar tetap pada kisaran normal. Pilar penatalaksanaan DM tipe 2 meliputi aspek edukasi, terapi gizi medis, latihan jasmani dan intervensi farmakologis (PERKENI, 2011). Salah satu komponen yang cukup penting adalah penatalaksanaan diet, yang diarahkan untuk mempertahankan kadar glukosa darah agar tetap terkontrol dan dipertahankan mendekati normal, mencapai dan mempertahankan kadar lipid serum normal, memberi cukup energi untuk mempertahankan atau mencapai berat badan normal, menangani atau menghindari komplikasi akut pasien dan meningkatkan derajat kesehatan secara keseluruhan melalui gizi yang optimal (Almatsier, 2005). 
Pasien diabetes menunjukkan kesulitan untuk mengatur sendiri perilaku diet mereka (Lin et al., 2008). Penyuluhan mengenai perencanaan makan (meal planning) telah diperoleh, namun lebih dari 50\% pasien tidak melaksanakannya (Waspadji et al., 2009). Berdasarkan studi pendahuluan peneliti pada bulan April 2012 melalui penyebaran kuesioner pada 20 orang penderita DM di wilayah kerja Puskesmas Kebonsari disimpulkan bahwa $85 \%$ penderita tidak patuh terhadap pengaturan diet. Ketidakpatuhan penderita DM tersebut disebabkan karena beberapa faktor yaitu tidak adanya waktu atau penderita terlalu sibuk, ketidaktahuan penderita akan pengelolaan DM, faktor ekonomi, dan sosial budaya (Puskesmas Kebonsari, 2012).

Jumlah penderita DM dari tahun ke tahun cenderung mengalami peningkatan. Berdasarkan data dari International Diabetes Federation (IDF), pada tahun 2030 mendatang sebanyak 552 juta di dunia orang akan terkena diabetes. Terjadi peningkatan sekitar 200 juta orang dari jumlah penderita tahun 2011 yang mencapai 346 juta orang. Data tahun 2009 lalu, jumlah penyandang DM di dunia mencapai 285 juta orang (Hidayat, 2011). WHO memprediksi kenaikan jumlah penyandang DM di Indonesia dari 8,4 juta pada tahun 2000 menjadi sekitar 21,3 juta pada tahun 2030 . International Diabetes Federation (IDF) pada tahun 2009, memprediksi kenaikan jumlah penyandang DM di Indonesia dari 7,0 juta pada tahun 2009 menjadi 12,0 juta pada tahun 2030 (PERKENI, 2011). Prevalensi DM tipe 2 di Indonesia mencapai hampir 80\% (Kemenkes, 2009). Jumlah penderita DM yang semakin tinggi tersebut membawa Indonesia menduduki peringkat keempat di dunia setelah India, China dan Amerika Serikat.

Arsana (2011) menyebutkan bahwa kontrol glikemik pasien sangat dipengaruhi oleh kepatuhan pasien terhadap anjuran diet meliputi, jenis dan jumlah makanan yang dikonsumsi dan ketidakpatuhan merupakan salah satu hambatan untuk tercapainya tujuan pengobatan dan juga akan mengakibatkan pasien memerlukan pemeriksaan atau pengobatan yang sebenarnya tidak diperlukan. Hal ini memerlukan perhatian dan penanganan serius dari tenaga kesehatan termasuk perawat untuk menurunkan angka kejadian DM yang salah satunya adalah dengan patuh dalam melaksanakan program diet (Anggina, 2010).

Diabetes Self Management Education (DSME) yang mengintegrasikan lima pilar penatalaksanaan DM menekankan intervensi perilaku secara mandiri (Norris et al., 2002). Para peneliti telah mengidentifikasi beberapa keterampilan khusus yang disebut manajemen diri yang membantu merubah berbagai faktor yang berhubungan dengan kepatuhan yang pada akhirnya dapat membantu merubah gaya hidup (Kelly, 2008). DSME menggunakan metode pedoman, konseling, dan intervensi perilaku untuk meningkatkan pengetahuan mengenai diabetes dan meningkatkan keterampilan individu dan keluarga dalam mengelola penyakit DM (Jack et al., 2004). Pendekatan pendidikan kesehatan dengan metode DSME tidak hanya sekedar menggunakan metode penyuluhan baik langsung maupun tidak langsung namun telah berkembang dengan mendorong partisipasi dan kerjasama diabetesi dan keluarganya (Glasgow \& Anderson, 1999). Metode ini diperlukan pada diabetes sejak metode tradisional yang menempatkan pasien pada peran pasif tidak lagi memadai untuk menangkap kompleksitas perawatan dan sifat penyakit yang tidak hanya membutuhkan tenaga kesehatan tetapi juga peran aktif pasien dalam perawatan (Anderson \& Funnel, 2005).

Penelitian Ariyanti

menyebutkan bahwa setelah dilakukan DSME mengenai meal planning, responden menjadi tahu jenis makanan yang boleh dikonsumsi banyak dan makanan yang sebaiknya dikurangi. Penerapan edukasi dengan pendekatan prinsip DSME dapat menimbulkan kemampuan manajemen diri yang baik sehingga dapat meningkatkan perilaku kepatuhan diet pada penderita DM tipe 2 .

\section{BAHAN DAN METODE}

Penelitian ini menggunakan desain eksperimen semu (Quasy-experiment). Pada penelitian ini terdapat 2 kelompok yaitu 1) kelompok eksperimental diberi perlakuan berupa edukasi dengan pendekatan prinsip DSME; 2) kelompok kontrol mendapatkan 
perlakuan seperti biasa. Pada kedua kelompok dilakukan pre test dan post test.

Populasi dalam penelitian ini adalah penderita DM tipe 2 yang melakukan kunjungan di Puskesmas Pembantu Karah dan Pagesangan yaitu sebanyak 77 orang. Besar sampel yang digunakan dalam penelitian ini sebanyak 12 orang pada masing-masing kelompok perlakuan dan kelompok kontrol. Penelitian ini dilaksanakan pada bulan Mei 2012. Variabel independen dalam penelitian ini adalah edukasi dengan pendekatan prinsip Diabetes Self Management Education (DSME). Variabel dependen dalam penelitian ini adalah perilaku kepatuhan diet dengan sub variabel: 1) pengetahuan diet, 2) sikap kepatuhan diet dan 3) tindakan kepatuhan diet.

Penelitian ini menggunakan instrumen berupa kuesioner untuk mengetahui pengetahuan diet dan sikap kepatuhan diet, sedangkan tindakan kepatuhan diet diukur menggunakan catatan harian selama tujuh hari. Pengambilan data dilakukan selama tiga minggu. Minggu pertama dilakukan pre test, minggu kedua dilakukan intervensi edukasi dengan pendekatan prinsip Diabetes Self
Management Education (DSME) dan pada minggu ketiga dilakukan post test. Analisis statistik diperoleh dengan perangkat komputer menggunakan uji statistik Wilcoxon Signed Ranks Test dengan derajat kemaknaan $\mathrm{p}<0,05$ dan uji statistik Mann Whitney test dengan derajat kemaknaan $\mathrm{p}<0,05$.

\section{HASIL}

Hasil penelitian menunjukkan terdapat perubahan pengetahuan, sikap dan tindakan kepatuhan diet sebelum dan sesudah dilakukan edukasi dengan pendekatan prinsip DSME. Hasil uji statistik dengan menggunakan Wilcoxon Signed Rank Test dapat dilihat pada tabel 1, 2 dan 3. Penelitian ini juga memperoleh hasil bahwa terdapat perbedaan pengetahuan, sikap dan tindakan kepatuhan diet antara kelompok perlakuan yang telah diberikan edukasi dengan pendekatan prinsip DSME dan kelompok kontrol yang tidak diberikan edukasi dengan pendekatan prinsip DSME. Hasil uji statistik dengan menggunakan Mann Whitney U Test dapat dilihat pada tabel tabel 1, 2 dan 3.

Tabel 1 Pengetahuan diet responden pada kelompok perlakuan sebelum dan sesudah diberikan edukasi dengan pendekatan prinsip DSME dan kelompok kontrol tanpa diberikan edukasi dengan pendekatan prinsip DSME pada penderita DM tipe 2 di wilayah kerja Puskesmas Kebonsari Surabaya

\begin{tabular}{|c|c|c|c|c|c|c|c|c|}
\hline \multirow{3}{*}{ Kategori } & \multicolumn{4}{|c|}{ Perlakuan } & \multicolumn{4}{|c|}{ Kontrol } \\
\hline & \multicolumn{2}{|c|}{ Sebelum } & \multicolumn{2}{|c|}{ Sesudah } & \multicolumn{2}{|c|}{ Sebelum } & \multicolumn{2}{|c|}{ Sesudah } \\
\hline & $\Sigma$ & $\%$ & $\Sigma$ & $\%$ & $\Sigma$ & $\%$ & $\Sigma$ & $\%$ \\
\hline Baik & 1 & 8,3 & 9 & 75 & 0 & 0 & 2 & 16,3 \\
\hline Cukup & 6 & 50 & 3 & 25 & 8 & 66,7 & 7 & 58,3 \\
\hline Kurang & 5 & 41,7 & 0 & 0 & 4 & 33,3 & 3 & 25 \\
\hline Mean & \multicolumn{2}{|c|}{1,67} & \multicolumn{2}{|c|}{2,75} & \multicolumn{2}{|c|}{1,67} & \multicolumn{2}{|c|}{1,92} \\
\hline SD & \multicolumn{2}{|c|}{0,65} & \multicolumn{2}{|c|}{0,45} & \multicolumn{2}{|c|}{0,49} & \multicolumn{2}{|c|}{0,67} \\
\hline \multirow{2}{*}{ Uji statistik } & \multicolumn{4}{|c|}{$\begin{array}{l}\text { Wilcoxon Signed Rank Test } \\
\qquad \mathrm{P}=0,004\end{array}$} & \multicolumn{4}{|c|}{$\begin{array}{l}\text { Wilcoxon Signed Rank Test } \\
\qquad \mathrm{P}=0,083\end{array}$} \\
\hline & \multicolumn{8}{|c|}{$\begin{array}{c}\text { Mann Whitney U Test } \\
\mathrm{P}=0,003\end{array}$} \\
\hline
\end{tabular}


Tabel 2 Sikap kepatuhan diet pada kelompok perlakuan sebelum dan sesudah diberikan edukasi dengan pendekatan prinsip DSME dan kelompok kontrol tanpa diberikan edukasi dengan pendekatan prinsip DSME pada penderita DM tipe 2 di wilayah kerja Puskesmas Kebonsari Surabaya

\begin{tabular}{|c|c|c|c|c|c|c|c|c|}
\hline \multirow{3}{*}{ Kategori } & \multicolumn{4}{|c|}{ Perlakuan } & \multicolumn{4}{|c|}{ Kontrol } \\
\hline & \multicolumn{2}{|c|}{ Sebelum } & \multicolumn{2}{|c|}{ Sesudah } & \multicolumn{2}{|c|}{ Sebelum } & \multicolumn{2}{|c|}{ Sesudah } \\
\hline & $\Sigma$ & $\%$ & $\Sigma$ & $\%$ & $\Sigma$ & $\%$ & $\Sigma$ & $\%$ \\
\hline Positif & 5 & 41,7 & 10 & 83,3 & 8 & 66,7 & 5 & 41,7 \\
\hline Negatif & 7 & 58,3 & 2 & 16,7 & 4 & 33,3 & 7 & 58,3 \\
\hline Mean & \multicolumn{2}{|c|}{1,58} & \multicolumn{2}{|c|}{1,17} & \multicolumn{2}{|c|}{1,33} & \multicolumn{2}{|c|}{1,58} \\
\hline SD & & & \multicolumn{2}{|c|}{0,39} & \multicolumn{2}{|c|}{0,49} & \multicolumn{2}{|c|}{0,52} \\
\hline \multirow{2}{*}{ Uji statistik } & \multicolumn{4}{|c|}{$\begin{array}{l}\text { Wilcoxon Signed Rank Test } \\
\mathrm{p}=0,025\end{array}$} & \multicolumn{4}{|c|}{$\begin{array}{l}\text { Wilcoxon Signed Rank Test } \\
\mathrm{p}=0,083\end{array}$} \\
\hline & \multicolumn{8}{|c|}{$\begin{array}{c}\text { Mann Whitney U Test } \\
\mathrm{p}=0,039\end{array}$} \\
\hline
\end{tabular}

Tabel 3 Tindakan kepatuhan diet responden pada kelompok perlakuan sebelum dan sesudah diberikan edukasi dengan pendekatan prinsip DSME dan kelompok kontrol tanpa diberikan edukasi dengan pendekatan prinsip DSME pada penderita DM tipe 2 di wilayah kerja Puskesmas Kebonsari Surabaya

\begin{tabular}{|c|c|c|c|c|c|c|c|c|}
\hline \multirow{3}{*}{ Kategori } & \multicolumn{4}{|c|}{ Perlakuan } & \multicolumn{4}{|c|}{ Kontrol } \\
\hline & \multicolumn{2}{|c|}{ Sebelum } & \multicolumn{2}{|c|}{ Sesudah } & \multicolumn{2}{|c|}{ Sebelum } & \multicolumn{2}{|c|}{ Sesudah } \\
\hline & $\Sigma$ & $\%$ & $\Sigma$ & $\%$ & $\Sigma$ & $\%$ & $\Sigma$ & $\%$ \\
\hline Patuh & 0 & 0 & 6 & 50 & 2 & 16,7 & 2 & 16,6 \\
\hline Cukup Patuh & 4 & 33,3 & 5 & 41,7 & 4 & 33,3 & 5 & 41,7 \\
\hline Kurang patuh & 8 & 66,7 & 1 & 8,3 & 6 & 50 & 5 & 41,7 \\
\hline Mean & \multicolumn{2}{|c|}{1,33} & \multicolumn{2}{|c|}{2,42} & \multicolumn{2}{|c|}{1,67} & \multicolumn{2}{|c|}{1,75} \\
\hline SD & \multicolumn{2}{|c|}{0,49} & \multicolumn{2}{|c|}{0,67} & \multicolumn{2}{|c|}{0,78} & \multicolumn{2}{|c|}{0,75} \\
\hline \multirow{2}{*}{ Uji statistik } & \multicolumn{4}{|c|}{$\begin{array}{l}\text { Wilcoxon Signed Rank Test } \\
\qquad \mathrm{p}=0,002\end{array}$} & \multicolumn{4}{|c|}{$\begin{array}{l}\text { Wilcoxon Signed Rank Test } \\
\qquad \mathrm{p}=0,564\end{array}$} \\
\hline & \multicolumn{8}{|c|}{$\begin{array}{c}\text { Mann Whitney U Test } \\
\mathrm{p}=0,036\end{array}$} \\
\hline
\end{tabular}

\section{PEMBAHASAN}

Hasil penelitian menunjukkan bahwa terdapat peningkatan pengetahuan responden di wilayah kerja Puskesmas Kebonsari Surabaya. Data menunjukkan bahwa pada kelompok perlakuan setelah diberikan edukasi dengan pendekatan prinsip DSME, 9 (75\%) orang memiliki pengetahuan yang baik tentang diet. Hasil penelitian ini mendukung penelitian Ariyanti (2012) yang menyatakan bahwa setelah dilakukan DSME mengenai meal planning, responden menjadi tahu jenis makanan yang boleh dikonsumsi banyak dan makanan yang sebaiknya dikurangi. Penelitian Rettig BA (1996) dalam (Norris et al., 2002) terkait DSME juga menunjukkan pengaruh bahwa terdapat pengaruh DSME terhadap perubahan pengetahuan penderita DM tipe 2 .

Pengetahuan merupakan domain penting terbentuknya tindakan seseorang. Pengetahuan diperoleh setelah seseorang melakukan penginderaan terhadap objek tertentu (Notoatmodjo, 2003). Proses pembelajaran dimaksudkan untuk memberikan pengetahuan pada penderita sehingga terjadi perubahan proses informasi, pengambilan keputusan dan emosi yang pada akhirnya terjadi proses kontrol cognator dalam otak agar melakukan mekanisme belajar dan adaptasi (Nursalam, 2008). Notoatmodjo (2003) menyatakan berbagai faktor yang mempengaruhi pengetahuan 
seseorang antara lain usia, pendidikan dan pengalaman. Perubahan pengetahuan terjadi pada kelompok perlakuan dikarenakan adanya minat dan kesadaran responden dalam pengaturan diet yang benar sebagai salah satu faktor yang dapat menurunkan gula darah. Edukasi yang diberikan secara bertahap dengan cara ceramah, diskusi, sharing sesama penderita yang lebih banyak melibatkan responden, keluarga dan diulangulang serta dilakukan review sebelum berlanjut ke pembahasan berikutnya sehingga lebih cepat dan mudah diterima. Adanya booklet yang menjadi pegangan juga berpengaruh sehingga edukasi tidak hanya berlangsung pada saat bertatap muka tetapi dapat dilakukan mandiri oleh responden.

Edukasi dengan pendekatan prinsip DSME yang dilakukan selama empat kali pertemuan mampu menimbulkan minat dan kesadaran responden pada kelompok perlakuan karena melibatkan responden secara langsung. Minat dan keterlibatan responden maupun keluarga dalam proses pemberdayaan penderita sangat diperlukan untuk kesuksesan program pemberdayaan dan kemandirian penderita DM tipe 2 yang dapat menimbulkan kepatuhan dalam hal pengaturan makan. Hal ini sesuai dengan yang dikemukakan Roger (1974) dalam Efendi \& Makhfudli (2009) bahwa dengan adanya pengkondisian pembelajaran akan terjadi perubahan perilaku seseorang dimulai dengan perubahan pada tingkat pengetahuan yaitu timbul pemahaman dan kesadaran (awareness). Notoatmodjo (2007) juga menyebutkan bahwa tingkat pengetahuan seseorang juga dipengaruhi oleh faktor eksternal seperti ketersediaan informasi, sarana prasarana, dukungan keluarga dan proses pembelajaran.

DSME yang dilakukan secara home visite, diskusi, sharing dengan penderita yang lain lebih mudah membuat responden memahami dan menerima materi untuk memori jangka panjang karena edukasi yang dilakukan bertumpu pada pendekatan interpersonal. Booklet dalam hal ini juga berperan sebagai pedoman karena didalamnya terdapat aturan, jumlah dan jenis makanan sesuai kalori yang dihabiskan dan makanan pengganti sehingga penderita dapat dengan mudah untuk melakukan perencanaan makan. Hal ini senada dengan penelitian Norris et al. (2002) yang menyatakan menyatakan bahwa pasien yang menerima intervensi edukasi menimbulkan manajemen diabetes yang lebih baik. Manajemen diabetes tersebut termasuk kepatuhan diet dan perubahan perilaku. Ketika pasien menerima pembelajaran, pasien memiliki kemampuan dan tahu bagaimana cara memanajemen penyakit. Faktor pengalaman juga akan sangat berpengaruh terhadap pengetahuan seseorang. Penderita yang lebih lama menderita DM telah memilki banyak pengalaman mengenai penatalaksanaan diabetes termasuk dalam hal pengaturan makan. Memiliki pengalaman yang banyak berbanding lurus dengan peningkatan pengetahuan pada seseorang. Pengalaman yang dimaksud adalah pengalaman yang bisa membuat hidup seseorang bisa menjadi lebih baik (Suriasumantri, 2001).

Pada pengukuran akhir yang dilakukan pada kelompok perlakuan masih terdapat tiga orang $(25 \%)$ responden yang memiliki pengetahuan diet termasuk dalam kategori sedang. Hal ini kemungkinan dikarenakan penderita tersebut memiliki tingkat pendidikan SD sehingga sulit untuk menerima informasi mengenai diet diabetes mellitus dan usia responden yang berada pada masa presenium juga menyulitkan seseorang untuk dapat menerima dan memahami informasi yang diberikan. Tingkat pendidikan responden yang termasuk SD mempengaruhi proses belajar, semakin tinggi pendidikan seseorang maka makin mudah orang tersebut untuk menerima informasi tentang kesehatan. Responden yang berada pada usia 45-60 tahun dimana usia tersebut memasuki masa usia presenil yang mulai menunjukkan adanya penurunan fungsi tubuh dan lebih mengutamakan ketenangan jiwa daripada kesehatan.

Perubahan yang terjadi pada kelompok kontrol tidak sebesar kelompok perlakuan. Hal ini kemungkinan disebabkan kelompok kontrol tidak mendapatkan edukasi dengan pendekatan prinsip DSME tetapi responden tetap menerima informasi mengenai diet dari petugas kesehatan saat mereka melakukan periksa kesehatan namun tidak spesifik, hanya terbatas pada apa yang diperbolehkan dan dilarang untuk dimakan. Perbedaan lokasi tempat tinggal antara kelompok perlakuan dan kelompok kontrol yang berbeda wilayah dengan jarak yang cukup jauh tidak memungkinkan responden 
kelompok perlakuan dan kelompok kontrol untuk bertemu. Kelompok perlakuan dan kelompok kontrol juga tidak melakukan kontrol kesehatan di tempat yang sama. Kebebasan mengakses informasi bisa saja mempengaruhi peningkatan pengetahuan pada kelompok kontrol. Responden dalam kelompok kontrol juga cukup aktif bertanya dan memiliki minat yang baik dalam melakukan pengaturan diet yang benar. Hal ini menjadi alasan terjadinya perubahan pengetahuan pada kelompok kontrol walaupun perubahan yang terjadi kurang berarti dikarenakan tidak ada pembelajaran yang spesifik mengenai pengaturan diet.

Hasil penelitian ini pun menunjukkan bahwa terdapat peningkatan jumlah responden yang mempunyai sikap positif yaitu 10 orang $(83,3 \%)$ setelah dilakukan edukasi dengan pendekatan prinsip DSME pada kelompok perlakuan. Hal ini sesuai dengan penelitian Rettig BA (1996) terkait DSME yang menunjukkan pengaruh terhadap perubahan sikap penderita DM tipe 2 (Norris et al., 2002). Hasil penelitian ini juga diperkuat oleh penelitian Lukman (2010) yang menyatakan bahwa DSME berpengaruh terhadap perubahan sikap positif penderita DM tipe 2 dalam pengelolaan diabetes mandiri.

Azwar (2003) menjelaskan bahwa sikap seseorang dibangun oleh tiga struktur dasar yaitu kognitif, afektif dan konatif. Kognitif sebagai representasi kepercayaan dan keyakinan terhadap suatu objek tertentu. Struktur ini menjadi landasan paling dasar sikap seseorang. Afektif menunjukkan perasaan dan kondisi emosional subjektif terhadap objek tertentu. Perasaan emosional ini membuat seseorang mempertahankan sikapnya walaupun belum tentu sikap yang ditunjukkan merupakan sikap positif. Struktur konatif lebih mengarah pada kecenderungan perbuatan dan tingkah laku seseorang terhadap suatu objek. Hal tersebut memberikan gambaran dan alasan mengapa responden memiliki sikap yang negatif dan ada yang positif.

Perubahan sikap yang terjadi pada kelompok perlakuan disebabkan karena adanya kemauan responden untuk memperbaiki keadaan kesehatannya, edukasi dengan pendekatan prinsip DSME diberikan secara bertahap dan berkelanjutan, edukasi lebih menekankan pada diskusi dan sharing dan adanya dukungan keluarga. Adanya kemauan penderita membuka peluang untuk terjadi perubahan sikap seseorang terutama jika perubahan itu menyangkut masalah kesehatannya. Ahmadi (1991) dalam Lukman (2010) bahwa sikap seseorang dipengaruhi oleh dua hal yaitu faktor internal yang berupa daya pilih seseorang untuk memilih atau menolak pengaruh yang datang dari luar dan faktor eksternal yang dapat berupa interaksi antar manusia.

Edukasi dengan pendekatan prinsip DSME yang diberikan secara bertahap dan berkelanjutan, memberikan kesempatan pada responden untuk menerima dan merespon edukasi yang diterima. Sesuai dengan yang dikemukakan Notoatmodjo (2007) bahwa menerima dan merespon merupakan tingkatan sikap seseorang. Penderita akan lebih mudah menerima berbagai masukan yang diberikan karena terdapat tenggang waktu untuk memilih sikap mana yang baik untuk kesehatannya. Proses diskusi dan sharing menjadi hal yang sangat penting dalam pelaksanaan edukasi dengan pendekatan prinsip DSME yang menekankan keterlibatan penderita, penderita lain dan keluarga secara langsung. Hal ini memberikan ruang bagi responden untuk menyampaikan keluh kesahnya, bertukar informasi dan solusi, untuk kemudian diberikan motivasi dan masukan yang bersifat membangun. Hiswani (2008) yang menyatakan bahwa edukasi kesehatan dengan menggunakan metode diskusi dan sharing dengan cara persuasif dapat menyentuh aspek perirasa (sikap) seseorang.

Dukungan keluarga juga semakin memperkuat perubahan sikap penderita. Anggota keluarga juga ikut berperan serta dalam pelaksanaan edukasi dengan pendekatan prinsip DSME dengan melakukan pendampingan, memberikan masukan dan menjadi pengingat penderita agar patuh terhadap aturan makan yang dianjurkan. Faktor dukungan keluarga memiliki andil yang cukup besar pada sikap seseorang. Friedman (2003) yang menyebutkan bahwa anggota keluarga akan lebih mudah menerima suatu informasi, jika informasi tersebut didukung oleh anggota keluarga lainnya.

Azwar (2003) menjelaskan bahwa edukasi kesehatan merupakan suatu bentuk persuasi dalam usaha melakukan perubahan 
sikap dengan memasukkan ide, pikiran atau fakta melalui pesan komunikasi. Sebenarnya pesan tersebut disampaikan secara sengaja dengan maksud untuk menimbulkan kontradiksi dan inkonsistensi diantara komponen sikap sehingga mengganggu kestabilan sikap dan membuka peluang terjadinya perubahan yang diharapkan. Cara ini efektif apabila sikap atau perilaku yang hendak dirubah tersebut ada kaitannya dengan kesehatan. Perubahan sikap yang terjadi diikuti dengan perubahan keyakinan, perasaan emosi dan kecenderungan bersikap yang baik akan membuat penderita menjadi lebih mantap dalam mematuhi dietnya.

Pada pengukuran akhir yang dilakukan pada kelompok perlakuan masih terdapat dua orang $(16,7 \%)$ yang memiliki sikap negatif. Hal ini kemungkinan dapat dikarenakan responden tidak mau menerima atau menolak pengaruh yang datang dari luar, penderita tidak mau pola makannya diatur karena hanya akan menimbulkan stres yang nantinya dapat memperparah kondisi kesehatannya dan responden merasa bahwa ketika tidak ada keluhan maka tidak perlu untuk melakukan pengaturan makan.

Pada kelompok kontrol terjadi perubahan sikap yang semula 8 responden $(66,7 \%)$ termasuk dalam kategori positif menjadi 5 responden $(41,7 \%)$ yang termasuk dalam kategori positif. Penurunan skor antara pre test dan post test yang pada kelompok kontrol terjadi kemungkinan dikarenakan karena kurangnya pengetahuan tentang pentingnya pengaturan makan pada DM dan tidak adanya dukungan yang berkelanjutan layaknya edukasi dengan pendekatan prinsip DSME juga berpengaruh terhadap perubahan sikap seseorang.

Pada penelitian ini pun diperoleh hasil bahwa edukasi dengan pendekatan prinsip DSME berpengaruh terhadap tindakan dalam mematuhi diet. Hal ini ditunjukkan dengan adanya perubahan tindakan kepatuhan diet dimana 6 orang (50\%) menjadi patuh setelah diberikan edukasi dengan pendekatan prinsip DSME pada kelompok perlakuan. Hasil ini senada dengan hasil penelitian Ariyanti (2012) yang menyatakan bahwa setelah dilakukan DSME, klien melakukan diet 1-2x seminggu, sebagian besar responden belum menerapkan 3J dalam perencanaan makan, namun setelah dilakukan DSME, beberapa klien mencoba menerapkan makan sesuai jadwal dan jenis makanan yang dimakan walaupun dalam porsi jumlah belum sesuai dengan yang dibutuhkan. Hasil penelitian ini juga berkaitan dengan hasil penelitian Lukman (2010) menyatakan bahwa ada pengaruh DSME terhadap kemauan dan kemampuan pelaksanaan pemantauan BB dan IMT pada penderita DM tipe 2 dimana BB dan IMT adalah langkah awal untuk dapat melakukan perencanaan makan. Penelitian Wilson tahun 1987 dan Elshaw tahun 1994 dalam Norris et al. (2002) menunjukkan tidak ada pengaruh signifikan terhadap BB penderita DM tipe 2, tetapi ada peningkatan signifikan terhadap kemauan dan kemampuan penderita dalam melakukan pemantauan BB secara berkala.

Proses perubahan tindakan merupakan keberlanjutan dari perubahan pengetahuan dan sikap setelah memperoleh edukasi dengan pendekatan prinsip DSME, namun seseorang dapat bertindak atau berperilaku baru tanpa terlebih dahulu mengetahui makna dari stimulus yang diterimanya. Perilaku seseorang tidak harus didasari oleh pengetahuan dan sikap (Notoatmodjo, 2003). Perubahan tindakan yang dilandasi oleh perubahan pengetahuan dan sikap, pemahaman dan respon yang baik untuk mematuhi diet akan membuat upaya perubahan tindakan berlangsung lebih lama.

Laurence Green dalam Notoatmodjo (2007) menjelaskan bahwa perilaku seseorang ditentukan faktor predisposisi yang meliputi kepercayaan, nilai, persepsi yang berkenaan dengan motivasi seseorang untuk bertindak; faktor pendukung yang meliputi tersedianya fasilitas dan sarana kesehatan; dan faktor pendorong yang meliputi sikap dan perilaku petugas kesehatan, keluarga, atau petugas lain yang merupakan kelompok referensi dari perilaku masyarakat.

Perubahan tindakan terjadi karena adanya persepsi dan keyakinan bahwa dengan mematuhi diet akan terjadi perbaikan pada kondisi kesehatannya dan komplikasi dapat dicegah. Dukungan keluarga juga berpengaruh dalam membantu untuk mengatur makanan dan sebagai pengingat agar penderita selalu makan sesuai aturan yang telah ditetapkan. Fasilitas penunjang yaitu booklet juga memudahkan penderita untuk menyusun makanan yang harus dimakan. Persepsi dan keyakinan bahwa suatu hal dapat memperbaiki keadaan 
kesehatannya memungkinkan seseorang untuk mengenal dan memilih objek sehubungan dengan tindakan yang akan diambil. Sesuai dengan Notoatmodjo (2007) yang menyebutkan bahwa persepsi adalah tingkatan pertama dalam melakukan tindakan. Dukungan keluarga yang kurang juga berpengaruh pada tingkat kepatuhan dalam melakukan pengaturan makan. Booklet juga membantu penderita untuk memudahkan melakukan pengaturan makan sesuai aturan yang telah ditetapkan berdasarkan kondisi masing-masing penderita.

Proses yang diterapkan dalam pelaksanaan edukasi dengan pendekatan prinsip DSME adalah integrasi dari berbagai komponen faktor predisposisi, pendukung dan pendorong terjadinya perubahan perilaku dan tindakan penderita agar mampu meningkatkan kepatuhan terhadap pengaturan dietnya. Edukasi dengan pendekatan prinsip DSME berusaha memperkuat pemahaman dan kesadaran penderita melalui proses edukasi yang dilakukan secara bertahap dan berkesinambungan. Perubahan sikap juga menjadi bagian yang penting dalam pelaksanaan edukasi dengan pendekatan prinsip DSME sehingga nilai dan kepercayan penderita dapat diarahkan untuk patuh terhadap dietnya.

Hasil penelitian juga menunjukkan bahwa masih terdapat 5 orang $(41,7 \%)$ responden dalam kelompok perlakuan termasuk kategori cukup patuh dan 1 orang $(8,3 \%)$ termasuk kategori kurang patuh dalam melakukan diet. Hal ini kemungkinan dikarenakan rumitnya pengaturan makan diabetes, walaupun ada panduan berupa booklet, jika penderita beranggapan bahwa itu adalah suatu hal yang rumit maka mereka enggan untuk mencoba dan melaksanakannya. Hal yang juga berpengaruh terhadap tindakan kepatuhan adalah adanya anggapan bahwa pengaturan makan hanya diperuntukkan atau digunakan ketika gula darah mencapai jumlah yang sangat tinggi dan jika merasa ada gangguan/keluhan yang dirasakan. Lamanya menderita DM juga membuat para penderita putus asa dengan upaya pengelolaan DM dan berpikir bahwa upaya itu akan sia-sia.

Pengukuran tindakan pada kelompok kontrol menunjukkan tidak ada peningkatan yang signifikan bahkan pada beberapa responden terjadi penurunan skor. Hal ini dapat disebabkan karena tidak ada panduan seperti halnya booklet yang mempengaruhi kepatuhan pengaturan makan karena penderita tidak tahu jenis, jumlah dan jadwal makan yang telah ditetapkan sesuai kondisi kesehatannya masing-masing. Kelompok kontrol juga tidak mendapatkan informasi secara spesifik terkait pengaturan diet DM sehingga informasi parsial yang diterima tentang pengaturan diet menyulitkan terjadinya perubahan tindakan kepatuhan diet.

\section{SIMPULAN \& SARAN}

\section{Simpulan}

Simpulan dari penelitian ini Edukasi dengan pendekatan prinsip Diabetes Self Management Education (DSME) dapat meningkatkan pengetahuan, sikap dan tindakan kepatuhan diet pada penderita DM tipe 2 di wilayah kerja Puskesmas Kebonsari Surabaya.

\section{Saran}

Peneliti menyarankan: 1) perlu dilakukan sosialisasi kepada perawat di puskesmas untuk mengaplikasikan edukasi dengan pendekatan DSME dan memaksimalkan komponen DSME dalam penatalaksanaan DM tipe 2, 2) perlu dilaksanakan penelitian lebih lanjut terkait pelaksanaan DSME dengan besar sampel yang lebih besar dan waktu sesuai standar pelaksanaan DSME, 3) perlu adanya penelitian yang serupa dengan pengukuran yang lebih akurat seperti observasi secara langsung mengenai kepatuhan dalam melaksanakan pilar-pilar pengelolaan DM tipe 2 .

\section{KEPUSTAKAAN}

American Diabetes Association. 2005. Diagnosis and Classification of Diabetes Mellitus. Diabetes Care. http://care.diabetesjournals.org.

Tanggal 23 April 2012 pukul 16.30 WIB.

Anggina, L.L., Hamzah, A., Pandhit. 2010. Hubungan Antara Dukungan Sosial Keluarga Dengan Kepatuhan Pasien 
Diabetes Mellitus Dalam Melaksanakan Program Diet Di Poli Penyakit Dalam RSUD Cibabat Cimahi. Jurnal Penelitian Kesehatan Suara Forikes. ISSN: 2086-3098.

http://isjd.pdii.lipi.go.id/admin/jurna 1/edhknnov1019.pdf. $\quad$ Tanggal 4 April 2012.

Ariyanti, M. 2012. Peningkatan Self empowerment Penderita Diabetes Mellitus Tipe 2 dengan Pendekatan Diabetes Self Management Education (DSME) di Puskesmas Kebonsari Surabaya. Skripsi tidak dipublikasikan, Fakultas Keperawatan Universitas Airlangga Surabaya.

Arsana, P.M., Sutjiati, E., Lestari, D.P. 2011. Pengaruh Penyuluhan Gizi Terhadap Kepatuhan Diet Pasien Diabetes Mellitus Di Poli Gizi RSU Dr. Saiful Anwar Malang. Majalah Kesehatan

FKUB.http://elibrary.ub.ac.id/bitstre am/123456789/24771/8/\%28lengkap \%29.pdf. Tanggal 4 April 2012.

Funnel, M., Anderson, R. 2005. Patient empowerment: reflections on the challenge of fostering the adoption of a new paradigm. http://www.hphconferences.org/arch ive/vienna07/htm/plenaryabstracts/P atietEmpowerment.pdf. Tanggal 23 Maret 2012.

Glasgow, R. and Anderson, R. 1999. Moving for Compliance to Adherence is not enough: Something Entirely Different is Need. Diabetes Care, 22: 403-408. http://care.diabetesjournals.org/conte nt/22/12/2090.full.pdf+html. Tanggal 15 Januari 2012.

Jack, L., Liburd, L., Spencer, T., Airhihenbuwa, C.O. 2004.
Understanding the Environmental Issues in Diabetes Self-Management Education Research: A Reexamination of 8 Studies in Community-Based Settings. Ann Intern Med. 140:964-971.

Lin, C., Anderson, R. M., Hagerty, B. M., \& Lee, B. 2008. Diabetes selfmanagement experience: A focus group study of Taiwanese patients with type 2 diabetes. Journal of Nursing and Health Care of Chronic Illness in association with Journal of Clinical Nursing, 17(5a), 3442.http://www.ncbi.nlm.nih.gov/pub med/18093120. Tanggal 23 Maret 2012.

Lukman, A. 2010. Pengaruh Diabetes Self Management Education (DSME) terhadap Pengelolaan Diabetes Mandiri pada Penderita Diabetes Mellitus Tipe 2 di Wilayah Kerja Puskesmas Pacarkeling Surabaya. Skripsi tidak dipublikasikan. Fakultas Keperawatan Universitas Airlangga Surabaya.

Norris, S.L,. Lau, J., Smith, S.J., Schmid, C.H., Engelgau, M.M. 2002. Self Management Education for Adult with Type 2 Diabetes. A Metaanalysis of The Effect on Glicemic Control. Diabetes Care. 25 (7): 1159-1171.

http://www.ncbi.nlm.nih.gov/pubme d/12087014>. Tanggal 5 Januari 2012.

PERKENI. 2011. Konsensus Pengelolaan dan Pencegahan Diabetes Mellitus Tipe 2 di Indonesia. http://perkeni.net/. Tanggal 13 Maret 2012 jam 07.25 WIB.

Puskesmas Kebonsari. 2011. Data Kunjungan Pasien Puskesmas Kebonsari, Puskesmas Kebonsari. Surabaya. 